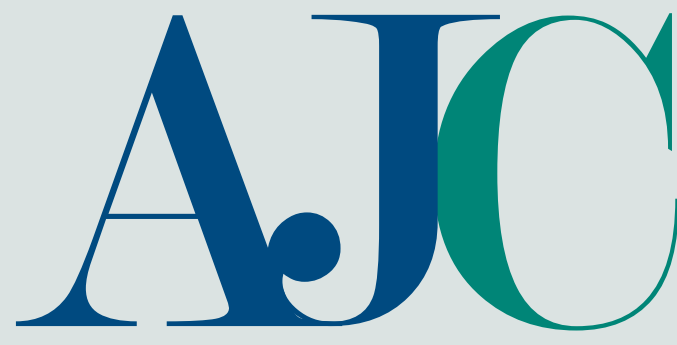

\title{
Volume 2 Issue 1
}

Academic Journal on Computing, Engineering and Applied Mathematics

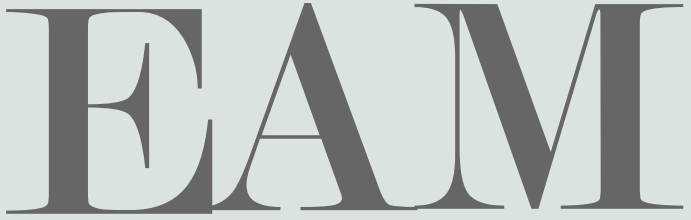

Academic Journal on Computing, Engineering and Applied Mathematics

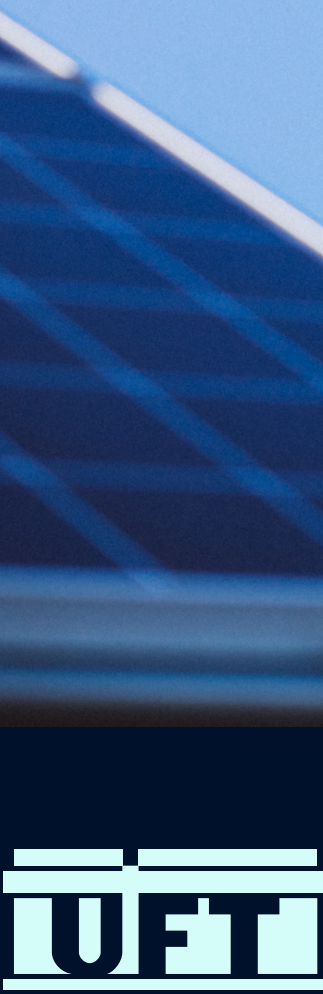




\title{
Editorial (Português): Academic Journal on Computing, Engineering and Applied Mathematics
}

\author{
Rafael Lima de Carvalho ${ }^{1}$ \\ ${ }^{1}$ Editor Chefe, Universidade Federal do Tocantins, Palmas-TO, Brasil
}

\begin{abstract}
A equipe editorial do AJCEAM vem trabalhando intensamente para melhorar a estruturação, organização e definição de objetivos para o crescimento e divulgação do periódico. Outrossim, sempre zelando pela qualidade dos artigos publicados. Por esta razão, este número possui dois importantes estudos conduzidos e revisados com excelência por nosso time qualificado de revisores.

O trabalho, intitulado "Day-Ahead Hourly Operation Planning of Distribution Networks with Photovoltaic Generation Integrated by Smart Inverters via Mixed-Integer Volt/Var Optimization Problems", escrito por da Bastos et. al. [1], aborda a modelagem e a resolução de um problema de OVV (Otimização Volt/Var) que busca minimizar os desvios de magnitude de tensão em Redes de Distribuição (RD) para o planejamento de véspera da operação horária com Geração Fotovoltaica Distribuída (GFD) integrada por inversores inteligentes para um fator de potência unitário.

Além disso, Carvalho, Almeida e Almeida [2], através de seu trabalho intitulado "Evaluation of a Sliding Window mechanism as Data Augmentation over Emotion Detection on Speech", avaliam a utilização de um mecanismo de janela deslizante como técnica de data augmentation no contexto de detecção de emoção em discursos. O método foi aplicado a três conjuntos de dados públicos: EMO-DB, SAVEE e RAVEDESS. Os experimentos reportam eficácia no aumento das taxas de reconhecimento de cerca de $11,95 \%$ no EMO-DB base, $22,76 \%$ no SAVEE e 18,82\% no RAVEDESS quando comparado a outras abordagens da literatura.

Por fim, agradecer aos editores Tiago da Silva Almeida e Warley Gramacho da Silva pela brilhante condução dos trabalhos durante as revisões, permitindo que os esforços dos autores fossem traduzidos nestes belíssimos trabalhos. Portanto, boa leitura e excelente aprendizado.
\end{abstract}




\section{Expediente}

\section{Editor-Chefe}

Rafael Lima de Carvalho, Brasil

\section{Editores}

Edeilson Milhomem Silva, Brasil

Rafael Lima de Carvalho, Brasil

Tiago da Silva Almeida, Brasil

Warley Gramacho da Silva, Brasil

\section{Comitê Científico}

Bruno Carrilho de Castro, Brasil

Cristiano Pires Martins, Brasil

Edeilson Milhomem Silva, Brasil

Edilaine Martins Soler, Brasil

José Paulo Codinhoto, Brasil

Junimar José Américo de Oliveira, Brasil

Kathy Camila Cardozo Osinski Senhorini, Brasil

Marcelo Lisboa Rocha, Brasil

Marcos Antônio Estremeto, Brasil

Marcos Marques da Silva Paula, Brasil

Mariela Cristina Ayres De Oliveira, Brasil

Maxwell Diógenes Bandeira de Melo, Brasil

Rafael Lima de Carvalho, Brasil

Rainei Rodrigues Jadejiski, Brasil

Sávio Dias, Brasil

Tiago da Silva Almeida, Brasil

Warley Gramacho da Silva, Brasil

\section{Realização}

Fundação Universidade Federal do Tocantins (UFT)

Quadra 109 Norte, Avenida NS-15, ALCNO-14 I Bloco III I sala 214 IPlano Diretor Norte I 77001-090 | Palmas / TO I Brasil

\section{Periodicidade}

Este periódico possui periodicidade semestral e utiliza a Licença Creative Commons 4.0 - CCBY 4.0. Contudo, a publicação dos artigos em modalidade avançada ou ahead of print, ou seja, tão logo os manuscritos aprovados sejam editados para publicação, é possível. O AJCEAM não possui taxas de publicação, tampouco de submissão de manuscritos, sendo totalmente gratuita para autores e leitores.

\section{Indexadores}

Google Acadêmico, desde 9 de maio de 2020

International Standard Serial Number - ISSN, desde 28 de maio de 2020

Crossref, desde 7 de junho de 2020

Revistas de Livre Acesso - LivRe, desde 24 de junho de 2020 


\section{REFERENCIAS}

[1] J. V. ALVES DE AZEVEDO BARROS, A. Flamarion Querubini Gonçalves, C. Francisco do Nascimento, and G. Guimarães Lage, "Day-ahead hourly operation planning of distribution networks with photovoltaic generation integrated by smart inverters via mixed-integer and mixed-complementarity volt/var optimization problems.” Academic Journal on Computing, Engineering and Applied Mathematics, vol. 2, no. 1, pp. 1-10, abr. 2021. [Online]. Available: https://sistemas.uft.edu.br/periodicos/index.php/AJCEAM/article/view/11285

[2] M. A. Farias da Silva, R. L. de Carvalho, and T. d. S. Almeida, "Evaluation of a sliding window mechanism as dataaugmentation over emotion detection on speech," Academic Journal on Computing, Engineering and Applied Mathematics, vol. 2, no. 1, pp. 11-18, abr. 2021. [Online]. Available: https://sistemas.uft.edu.br/periodicos/index.php/AJCEAM/article/view/11737 